Religiöse Individualisierung in historischer Perspektive

Religious Individualisation in Historical Perspective 



\section{Religiöse Individualisierung in historischer Perspektive Religious Individualisation in Historical Perspective}

Abschlussbericht für die zweite Förderphase der Kolleg-Forschungsgruppe 1013

Final Report of the Kolleg-Forschungsgruppe 1013 for the Second Funding Period

2013-2018

Herausgegeben von / Edited by

Riccarda Suitner, Martin Mulsow, Jörg Rüpke 
Die Drucklegung wurde durch die Deutsche Forschungsgemeinschaft (FOR 1080) finanziert.

ISBN 978-3-11-069637-0

e-ISBN (PDF) 978-3-11-069649-3

e-ISBN (EPUB) 978-3-11-069667-7

DOI https://doi.org/10.1515/9783110696493

\section{(cc) BY-NC-ND}

Dieses Werk ist lizenziert unter der Creative Commons Attribution-NonCommercial-NoDerivatives 4.0 International Lizenz. Weitere Informationen finden Sie unter http://creativecommons.org/licenses/by-nc-nd/4.0/.

\section{Library of Congress Control Number: 2020937740}

\section{Bibliografische Information der Deutschen Nationalbibliothek}

Die Deutsche Nationalbibliothek verzeichnet diese Publikation in der Deutschen Nationalbibliografie; detaillierte bibliografische Daten sind im Internet über http://dnb.dnb.de abrufbar.

(C) 2020 Riccarda Suitner et al., publiziert von Walter de Gruyter GmbH, Berlin/Boston Dieses Buch ist als Open-Access-Publikation verfügbar über www.degruyter.com.

Druck und Bindung: CPI books GmbH, Leck

www.degruyter.com 